Unequal Consumers: Consumerist healthcare technologies and their creation of new inequalities

Peer-reviewed author version

VISSER, Laura; Benschop, Yvonne W. M.; Bleijenbergh, Inge L. \& VAN RIEL, Allard (2018) Unequal Consumers: Consumerist healthcare technologies and their creation of new inequalities. In: Organization studies, 40 (7), p. 1025-1044.

DOI: $10.1177 / 0170840618772599$

Handle: http://hdl.handle.net/1942/26061 
See discussions, stats, and author profiles for this publication at: https://www.researchgate.net/publication/325249985

\section{Unequal Consumers: Consumerist healthcare technologies and their creation of new inequalities}

Article in Organization Studies · May 2018

DOI: 10.1177/0170840618772599

CITATIONS

0

4 authors, including:

Laura M Visser

Monash University (Australia)

6 PUBLICATIONS 16 CITATIONS

SEE PROFILE
READS

54

Allard van Riel

Hasselt University, Hasselt, Belgium and Radboud University, Nijmegen, th.. 79 PUBLICATIONS $\mathbf{2 , 9 5 4}$ CITATIONS

SEE PROFILE

Some of the authors of this publication are also working on these related projects:

Brand Communications View project

Relationship Marketing View project 


\section{Unequal consumers}

Consumerist healthcare technologies and their creation of new inequalities

This article examines how consumerist technology creates new inequalities among patients in healthcare. More specifically, we analyze a communication technology that presents a case of consumerization of patients. Using critical diversity literature, we aim to theorize how consumerism embedded in technology assumes a 'universal individual', creating a tension for healthcare professionals between acknowledging differences among patients while aiming for equal treatment of all patients. Based on our empirical analysis of so-called Personal Online Health Communities, we explore, at the microlevel, how healthcare professionals deal with this tension. We identify four different practices; lacking awareness of differences, downplaying differences, discomfort around acknowledging differences and actively accommodating differences. We theorize how they ultimately all create new inequalities.

\section{Key words}

consumerism; inequality; healthcare; technology 


\section{Introduction}

Healthcare organizing follows the private sector in that it has increasingly become marketized (Fotaki, 2010a; Lupton, 1997). More and more, healthcare takes a product-like form that can be traded on a market, where healthcare professionals appear as service providers following patients' wishes, and patients as (empowered) consumers who make autonomous and individualized choices (Fotaki, 2009; Lupton, 1997; Mol, 2008; Timmermans \& Oh, 2010). Although the underlying assumption is that marketization will improve efficiency and quality of care (Detmer, Bloomrosen, Raymond, \& Tang, 2008; Krist \& Woolf, 2011), scholars have also criticized this trend, especially when it comes to turning patients into consumers, which ignores the limits to controlling one's health, especially for certain groups in society (Burge, Devlin, Appleby, Rohr, \& Grant, 2005; Fotaki, 2006, 2009, 2010a, 2011, 2017; Jung, 2010; Victoor, Delnoij, Friele, \& Rademakers, 2012). In this article, we present a case of a communication technology that is based on a consumerist perspective, meaning that it aims to individualize patients' experiences with care provision by actively involving patients in making decisions about the 'products' they buy, and making them responsible for those decisions. We aim to show that even though it is positioned as a positive force, the consumerist perspective embedded in the assumed 'neutral' technology creates new inequalities between patients. More specifically, we explore the creation of these 
inequalities, especially in relation to how the consumerist technology individualizes patients and how healthcare professionals struggle to combine individualized service and equal treatment of all patients.

Existing literature on healthcare and consumerism has criticized the consumerization of patients, but we argue that the introduction of technology brings three distinct issues in this literature to the foreground that require further exploration. First, discussions on consumerism in healthcare often focus on choice (Caruana \& Crane, 2008; Fotaki, 2006, 2009; Gabe, Harley, \& Calnan, 2015; Victoor, Delnoij, et al., 2012), ignoring other important topics (especially when it comes to technology (Victoor, Friele, Delnoij, \& Rademakers, 2012)), such as access to care. Second, studies often examine consumerism at the macrolevel of discourse and policy-making (Crawshaw, 2012; Fotaki, 2009, 2010a, 2010b, 2017; Gabriel \& Lang, 2008), but the actual (micro-level) practices, especially of healthcare professionals operating under consumerism, have received less attention. Third, in general, the relations between inequality, healthcare technology, and consumerism have not received much attention in the literature. We examine how the interaction of technology and consumerism creates new inequalities in healthcare.

To better understand these aspects of consumerism in healthcare, we turn to the critical diversity literature. This literature focuses on issues of inequality and 
individualization (Benschop, 2011; Jonsen, Tatli, Özbilgin, \& Bell, 2013; Zanoni, Janssens, Benschop, \& Nkomo, 2010) and helps to unpack the individualization of patients as healthcare consumers. We use this literature to show that group-based differences seemingly cease to matter in individualized care, as consumerism assumes what we refer to as a 'universal individual' patient (i.e., the aspect of being individualized is universally applied). The individualized patient is an ideal abstraction of a patient, assumed capable of articulating healthcare needs and making informed decisions. Bringing in critical diversity literature, we demonstrate that individualization of differences conceals that not all patients fit this ideal. This creates a tension for healthcare professionals who treat patients as though they fit a universal and abstract ideal, while on the other hand they are confronted with the reality of patients' actual, diverse needs, desires, and abilities to express themselves. We apply insights from the critical diversity literature to unpack professionals' dealing with this tension.

We focus on answering the question(s) of how healthcare professionals deal with this tension at the micro-level to better understand how practices involved in using communication technology (re)produce social inequality. As such, the article makes two contributions. First, we theorize how the technology assumes a 'universal individual', able to articulate individual needs and desires for care provision affecting patients' access to the technology. The second contribution concerns the tension healthcare professionals 
experience in using the technology, by identifying four practices through which healthcare professionals deal with differences between patients. We theorize how all of these four practices allow healthcare professionals to ‘do difference without inequality', preventing actual systemic change in patents' lives and experiences with their illness from occurring. Although we frame these contributions in a healthcare context, they also translate to other contexts where consumerist technology is introduced to increase the inclusion of users, such as unemployment or student services (Josefsson \& Ranerup, 2003; Naidoo \& Williams, 2015; Warschauer, 2004).

We make these contributions in the empirical context of personal online health communities (POHCs). An organization called ParkinsonNet set up these POHCs for patients who are chronically ill (Parkinson's disease), to support online interactions with their own healthcare professionals. Using a qualitative case-study design, we collected data on these POHCs through conducting 31 semi-structured interviews with patients and healthcare professionals using the POHCs, and by collecting documents. In the interviews, we asked both groups to talk about the roles of patients and healthcare professionals on the POHCs and to reflect on the (dis)advantages of using a POHC. In addition, we analyzed three documents promoting the POHCs, which allowed us to examine how consumerism is present in the setting up of the POHCs. 
In the next sections, we discuss our theoretical background, drawing on critical diversity literature, and our methods for data collection and analysis. Thereafter, we present the results of our analysis, which we discuss in broader theoretical and practical contexts in our discussion section.

\section{Theoretical background}

\section{Consumerism and healthcare}

Consumerism has recently become a relevant topic for management and organization scholars as it raises questions about how organizing occurs and who is involved in those processes (Gabriel, Korczynski, \& Rieder, 2015). Cônsumerism can be defined as a process whereby exchanges between people become ruled by a market ideology, resulting in users becoming consumers who actively make individualized choices about the services or products they 'demand' (Baudrillard, 1998; Bauman, 2007). Because of its foundation in a neoliberal zeitgeist, scholars criticize consumerism for potentially leading to exploitation as users become increasingly responsible for producing the service or product they are after, a phenomenon often referred to as 'prosumption' (Arnould \& Cayla, 2015; Bauman, 2011; Fontenelle, 2015; Gabriel et al., 2015; Ritzer \& Jurgenson, 2010). 
In relation to the healthcare sector, consumerism is even more criticized because it concerns people in vulnerable positions who cannot always be expected to be responsible for actively engaging in their own care provision (Dent, 1995; Fotaki, 2009; Gabe et al., 2015; Gabriel et al., 2015; Long, 1999; Lupton, 1997; Mol, 2008; Turner \& Samson, 1995). As a prominent scholar on the topic of consumerism in healthcare, Fotaki (2009) states that consumerism has been "elevated to a moral doctrine and a vehicle of freedom, power and happiness" (p. 88), resulting in a situation where individuals are assumed to have their individual empowered voice, but are also expected to manage their disease and be responsible for their own healthcare outcomes. Long (1999) has referred to this as the 'tyranny' of the consumer as it collapses the many complex roles that patients might play into a simplified role of an individualized consuming patient. Many scholars have examined the complexity of consumerism in healthcare in recent years, ranging from examinations of policy-making and implementation (Fotaki, 2006, 2010a; Needham, 2009; Ravn, Frederiksen, \& Beedholm, 2016; Victoor, Friele, et al., 2012), to changing professional ethics (Dwarswaard, Hilhorst, \& Trappenburg, 2011; Stevenson, Leontowitsch, \& Duggan, 2008; Timmermans \& Oh, 2010; Tonkens, Broer, van Sambeek, \& van Hassel, 2013), and to patients’ behavior as they have become consumerized (Fotaki et al., 2008; Henwood, Harris, \& Spoel, 2011; Laing \& Hogg, 2002; Lupton, 1997; Mol, 2008; Tonkens, 2003; Victoor, Delnoij, et al., 2012). This 
literature provides valuable insights into the limitations of consumerism in healthcare especially from a macro-level policy perspective - showing the constraints on the alleged choices patients have or get, and questioning if we can even consider patients as (Fotaki, 2006, 2017).

\section{Consumerism and healthcare technology}

We build on these insights but also argue that the healthcare technology under examination in this article brings into focus three issues that remain underexplored in the literature, and need further attention: (1) a more in-depth focus on the issue of access to care (which is especially relevant in the context of technology), going beyond the widely explored topic of choice in healthcare, (2) zooming in on the micro-levêl of healthcare professionals' practices, especially because they play a large role in ensuring access to care, and ultimately, (3) the influence of consumerist technology on inequality.

Addressing the first issue, many scholars have critiqued the idea of choice as a myth in healthcare (Fotaki, 2006, 2009, 2010a; Mol, 2008; Victoor, Delnoij, et al., 2012). Although this critique is especially relevant from a healthcare policy perspective (where increasing choice seems to be the leitmotiv of policy-writing) we risk missing out on the issue of access to care. We argue that access is an especially important theme when introducing healthcare technology. Organizing care provision through technology has the potential to lead to the 
exclusion of specific groups, as the demands of technological tools are not within reach for every patient. Some patients might not be able to express their own interests, because they are confused, scared or simply too sick, and are in danger of being left behind (Tonkens, 2003, p. 8). However, how access to technology plays a role within this context is not well understood.

Regarding the second issue: although macro-level trends have been well described, there has been less focus on how consumerism trends are dealt with at the micro-level. Empirical discussions on consumerism tend to remain in the area of policy analysis, using discourse analysis as an analytical technique to show the norms and power processes behind the policies (Fotaki, 2006, 2010a; Needham, 2009; Ravn et al., 2016). The few studies that zoom in on the practices of patients and healthcare professionals, again, often focus on choice and the perceived responsibility of patients that comes with consumerism (Crawshaw, 2012; Henwood et al., 2011; McDonald et al., 2007; Stevenson et al., 2008; Victoor, Friele, et al., 2012). Especially the role of healthcare professionals and their engagement with consumerism remains underexposed, even though these professionals are important actors when it comes to providing access to care. Examinations of healthcare professionals tend to discuss marketization more generally, studying how it erodes their sense of professionalism and affects their (ethical) behavior as they are turned into service providers (Dwarswaard et 
al., 2011; Long, 1999; Timmermans \& Oh, 2010; Victoor, Delnoij, et al., 2012). An in-depth analysis of the different practices that healthcare professionals engage in will shed light on consumerist technology at the level of daily care provision.

Lastly, the technology brings up the issue of inequality in relation to consumerization. Inequality is an important theme in healthcare, because of the moral imperative that care should be accessible to all. In the healthcare literature, health inequality tends to be examined as inequality in health outcomes (Bartley, 2004; Rogers, 2006). In other words, healthcare literature focuses on difference in morbidity rates between groups from different genders, and racio-ethnic and class backgrounds. In this article, we are interested in the differences in processes of providing care, and especially access to care. Differences in access to care are sometimes acknowledged, but mainly conclude an article, rather than being the central topic of investigation (Burge et al., 2005; Fotaki, 2009; Jung, 2010; Victoor, Friele, et al., 2012).We posit the idea of a 'universal individual' as an important entry point for our analysis. Stressing the individual and her or his unique needs, consumerism assumes the existence of a 'universal individual'. The implicit assumption in consumerism is that individualized consumers all desire and are able to make individual demands. In other words, consumerism's emphasis on individuals and their needs comes with an assumption that 
individuality itself (and the expression of it) is universally shared and desired. Using critical diversity literature, we will further unpack this assumption.

\section{Critical diversity literature}

The lens of critical diversity studies helps to understand consumerization of patients, and especially the inequality in access to care that results from its individualization. This literature argues that such focus on individuality suggests that everyone can be 'different' in the same way, providing a meritocratic ideal of individuality as shared by all (Jonsen et al., 2013; Zanoni \& Janssens, 2004). Lorbiecki and Jack (2000) refer to this as the "ironic effect" of diversity management: by stressing how we all are different, and that these differences should be accommodated, we simultaneously erase the fundamental social basis of these differences, which is social categories. In other words, differences in social background become framed as individual uniqueness and this “individualism depoliticizes and essentializes difference, and silences systematic inequalities” (Jonsen et al., 2013, p. 276).

In relation to consumerization, we show that zooming in on the individual (which consumerization of patients does), potentially conceals the social groups these patients belong to (Zanoni \& Janssens, 2004; Zanoni et al., 2010). This means that consumerism embedded in healthcare technology targets an abstract individualized patient and so celebrates superficial differences rather than accommodates systematic differences. This 
creates a tension between accommodating differences among patients while aiming for equal treatment of all patients. This tension originates in healthcare professionals' strong ethics of care, where equality is one of the highest ideals (Hughes, McKie, Hopkins, \& Watson, 2005; Rogers, 2006). The healthcare technology, and the assumed 'universal individual' consumer, tries to marry both the relational of ethical care provision and the individuality of the consumer position (Fotaki, 2017). How this tension is produced through the technology, how healthcare professionals deal with this tension through engaging in different practices, and how this affects social inequality are questions we will answer based on this combination of insights.

\section{Methods}

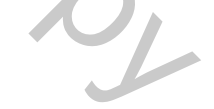

Our empirical cases are POHCs set up by ParkinsonNet, a foundation in the Netherlands that aims to improve the quality of life for patients with Parkinson's disease. The POHCs were part of a pilot project (called 'MyP@rkinsonCare’) intended to give patients a more active role in their own care provision. This pilot project assisted patients in using a POHC by providing practical support from Parkinson's nurse practitioners. Most patients were recruited via the professional network of these Parkinson's nurses. Some patients also heard about the pilot through other channels (Parkinson's-related social events and flyers circulated 
at healthcare facilities). The patients were the key actors in the POHCs, because they were able to decide who could join their community, but the Parkinson's nurses also played an important role in encouraging the use of the POHCs and assisting patients in navigating the communities.

\section{Data collection}

When we started collecting data for this article, about 100 patients were enrolled in the pilot project. The nurse practitioners helped us to select patients for our sample, which consisted of patients who were actively using the communities. We focused on active users since we wanted to understand the use of these POHCs, rather than reasons for why they were (not) used. A neurologist involved in setting up the pilot project estimated that one third of the patients were active users (= 33 patients), and we interviewed 18 of those based on the nurse practitioners' recommendations. Of these 18 patients, we then selected five patients with a large number of healthcare professionals involved in their online health community. We approached all 19 of these healthcare professionals (some of whom were involved in multiple patients’ POHCs) and ended up interviewing 13 (they were neurologists, physical therapists, nurse practitioners, occupational therapists or rehabilitation specialists). The other six healthcare professionals declined an interview because of time restrictions. 
The semi-structured interviews with patients were conducted face-to-face in patients' own homes and lasted between 45 and 90 minutes, with an average of about 60 minutes. We used a topic list for addressing different issues related to the POHCs, asking patients about their role on the POHCs and how they felt about using them and what they considered advantages and disadvantages.

We conducted the interviews with healthcare professionals in their own surroundings, being their office or a (consultation) room in a hospital. Five interviews were conducted over the phone upon the healthcare professional's request. Interviews with healthcare professionals lasted between 15 and 66 minutes, with an average of about 35 minutes. This broad range in interview times is caused by the difference between phone versus face-to-face interviews. Similar to the interviews with patients, we used a topic list while interviewing healthcare professionals. Those topics spoke to healthcare professionals' own role on the POHC as well as that of the patients. Furthermore, we discussed the different ways in which patients were using the community and the advantages and disadvantages of using the POHC.

All interviews were transcribed verbatim and analyzed using the Atlas.ti software package. Next to these 31 interviews (with 18 patients and 13 healthcare professionals), we also analyzed three documents written by ParkinsonNet that advertised the pilot project. The 
documents addressed different audiences (patients and healthcare professionals), and we used them to analyze how ParkinsonNet described the purpose of the pilot project.

\section{Data analysis}

During the interviews, we never used the word 'consumer'. Similarly, the documents do not refer to consumers in any explicit way. We collected the data without a pre-existing interest in consumerism, but the topic arose from our first analysis of the data and peer feedback we received from colleagues. After that, we returned to the data and eventually started focusing on healthcare professionals specifically, and how they dealt with the tension between acknowledging difference and equal treatment that is produced by consumerism embedded in the POHCs. To analyze our data from this starting point, we asked questions to our data such as: how is consumerism present in the POHCs; how do healthcare professionals talk about differences between patients; in what way do they talk about access to care provided through the POHCs; and what ethical dilemmas do these healthcare professionals face regarding these themes.

We coded our data based on these questions. Starting with the documents, we first identified how aspects common in consumerism, such as choice, responsibility and active involvement, were present in these documents. When we turned to the interviews, we identified how these themes were also present in the users' experience of the technology. We 
made special note of how healthcare professionals framed differences between patients. Ultimately this framing of differences became our main scheme for organizing our data in four categories, being lacking awareness of differences, downplaying differences, discomfort around acknowledging differences and actively accommodating differences.

We conducted a general interpretive qualitative analysis on the relevant quotes. This approach to qualitative data analysis entails that we understand what the interviewees said not as a form of truth, but as a social construction itself (Bryman \& Bell, 2012; Schwandt, 2000). The way consumerism is present in the POHCs is, thus, socially constructed by ParkinsonNet, healthcare professionals, and patients together, drawing on current societal discourses. We aimed not to take quotes at face value, but to analyze the deeper layers behind the superficial text produced in the interview. Moreover, we see the interview text as created in interaction with the interviewer, and an effect of the similarities and differences in social categories between interviewee and interviewer as well. The interviewer (the first author) identified as a young woman in the early stages of her academic career. Her middle-class background played a role in her interviews with healthcare professionals and patients who sometimes were from different class backgrounds (although most healthcare professionals were middle and upper middle class). Most of the patients fell into the middle-class category, although two of them could be identified as working class. In general, though, the patients 
interviewed seemed relatively privileged despite their illness; they already had demonstrated the skills to be able to use the POHCs and were able to reflect on their own position. These privileged positions (and the fact that the interviewer also held a privileged position) made it easier to conduct the interview, because of a shared knowledge and language, especially around the use of technology. At the same time, however, it may indicate the exclusion of other groups of patients (based on class and ethnicity most prominently) making us aware of the role of social categories in data-collection and analysis.

\section{Patients as healthcare consumers}

Our results section is based on a two-pronged approach. First, we discuss consumerism as it is present in the POHCs. Second, we discuss how professionals deal with the tension between acknowledging differences and equal treatment. We distinguish four different practices for dealing with this tension, lacking awareness of differences, downplaying differences, discomfort around acknowledging differences, and actively accommodating differences. Our analysis focuses on the inequality embedded in healthcare professionals practices.

To better understand how consumerism is present in the POHCs, let us start with how ParkinsonNet, the initiator of the POHCs, themselves describe the POHCs. Below is an excerpt from a flyer given to patients who might be interested in setting up a POHC. 
Are you dealing with healthcare providers that hardly know each other and don't collaborate enough? You want to be more actively involved in decision-making about your own treatment, but don't know how you could do this? [...] MyP@rkinsoncare's central aim is to give you more control over and improve the coordination of your care.

Patient flyer ParkinsonNet

Many patients don't know how they can play an active role and how they can be involved in thinking about their own care and treatment. Despite efforts from healthcare professionals to discuss different care options, this remains a difficult issue. The project MyP@rkinsoncare aims to give the patient a more central role and to improve the coordination between the different aspects of treatment.

General Practitioner flyer ParkinsonNet

The flyer for patients starts with a number of questions about things that could potentially be improved in the care provision process. Similar to the flyer for general practitioners, the patient flyer emphasizes the need for improvement of both healthcare professionals' and patients' involvement, especially when it comes to patients being more actively involved in deciding about their own care. Such taking ownership of one's own care fits neatly in 
consumerism that centralizes individual needs and celebrates the importance of asking for specific forms of care, while also being made responsible for this. The patient is presented as taking a more central position within the POHCs, and the POHCs create opportunities to express and address individual needs.

The more active role advocated in the flyers might also entail that patients take on some new tasks, as the occupational therapist below demonstrates.

What I like is that, through the POHC, you can put more responsibility with the patient. She [a specific patient] asked me something, but it was [a question] for the neurologist. [so I said] "Why don't you ask that through the POHC to your own neurologist?”. In the past, I felt the urge to go directly to him; “ok, I'll make a call to discuss the problem”. So, I just think that for the people, you actually put more responsibility with the patient.

Finn, occupational therapist (m)

This occupational therapist describes how POHCs legitimize putting more responsibility for care provision onto the patient. The occupational therapist clearly draws on the prosumer image (Ritzer, Dean, \& Jurgenson, 2012; Ritzer \& Jurgenson, 2010). By relaying the task of addressing questions to the (appropriate) healthcare professionals to the patient, the patient becomes part of this aspect of care provision. As the occupational therapist describes, 
previously he did not assume the patient was responsible for relaying information or questions to other healthcare providers. In this way, healthcare professionals might benefit from the introduction of the POHC and consumerism embedded in it as it could potentially decrease their workload.

Patients show different responses to this shift: some are more positive than others:

If you have some questions yourself or something. Then you can, through this system, look at your question and make it known. And my experience is that they, actually, respond quite quickly.

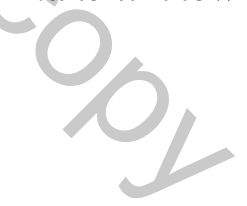

Zach, patient (m)

He [the Parkinson's nurse] tells me "you should keep a diary on the POHC". Well, I say, that is too much for me. I will have to spend extra time at the computer every day. And then I have to be so alert about what is going on. I also don't like that, because I don't only have, I am not just Parkinson's.

Alicia, patient (w) Although Zach praises the fact that he can ask questions and can get a quick response (rather than having to wait until the next appointment or calling the doctor's office), Alicia talks about the burden the POHC brings. It becomes clear from her excerpt that she feels pressured to comply with this requirement to engage on a regular basis with her disease, but also that 
she is able to resist this. Therefore, these patients present a complex view of what consumerism and the POHCs mean for them and their relationship to their disease. It can both be an opportunity to share your questions as needed as well as burden you with a duty to do so.

Next to having different levels of desire to do so, patients also describe different abilities for engaging with the technology:

Some are also a lot more articulate in writing than others. And, well, I don't really

have issues with that. I can write down my thoughts, my opinions quite easily.

Because you're used to that, from your work. But not everyone has that.

Howard, patient $(m, 75)$

But, it comes down to the initiative patients take. I also know people that don't even dare to say anything. Just take everything without questioning.

Peter, patient $(m, 71)$

Although different patients use the POHCs differently, the most poignant difference might be found in who even has access to the POHCs in the first place. Although the text of the flyers creates a 'universal individual patient', suggesting that all patients can and want to discuss their individual needs on the POHCs, these patients paint a different picture. Howard describes the importance of his ability to write down his thoughts for his use of the POHCs. 
Being able to express what is on your mind in a way that is comprehensible for others is something that he describes as being learned through his work (he is a retired municipality official). However, Howard also states that not everyone has the same background. Similarly, Peter talks about daring to talk, but describes this in terms of taking initiative. He argues that some people are afraid to say or question some things. The way these interviewees speak about the different abilities suggests that these are determined by personality or past life experiences. Of course, this reflects a highly individualized explanation, which we will also come across (and analyze in further depth) below when we continue with healthcare professionals.

\section{Dealing with differences}

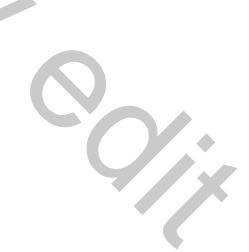

Overall, the above quotes show the implicit assumption of consumerism in the POHCs that all patients have these consumer abilities. This assumption creates what we have theoretically framed as the 'universal individual', which signals a tension between individualizing service and treating every patient equally. In the next sections, we will show the practices with which healthcare professionals engage with this tension. In this section, we will discuss how healthcare professionals struggle to combine the individualized patient ideal with the reality 
of differences among patients they encounter (i.e., not all patients are equal). We discuss four different practices that healthcare professionals engage in to deal with this tension.

\section{Lacking awareness of differences}

The first practice is displaying a lack of awareness that differences between patients exist. Based on the sample of patients we interviewed, we would argue that only a selective group joined the POHCs. Overall, healthcare professionals acknowledged this, but this neurologist was one of the few who seems less able or willing to do so. He was asked by the interviewer if he noticed any patterns in terms of which patients had joined the pilot project.

[I: in terms of age and social class of patients, did you notice anything there?] I don't recall. No. I think it's a bit of a mixed population, you know. Also some older people.

\section{David, neurologist (m)}

In this excerpt, the neurologist seems unaware that certain groups have easier access to the POHCs than others, suggesting that he sees no differences. Although he does talk about a 'mixed population' (implicitly mentioning differences), he denies the suggestion of the interviewer that some groups might be overrepresented. Interestingly, he does make a comment about older people, signaling that age is a category where he expected an underrepresentation of certain groups but he does not do the same for social class, even 
though the interviewer asked about both categories. This might indicate that age differences are easier to discuss than social class differences. Furthermore, the interviewer felt that the neurologist was irritated or even offended that she would bring up such issues, perhaps because he considered them not worth it (or even ethical) to focus on. As such, the neurologist constructs differences between patients as present but simultaneously non-existent, as he views all patients as being equal.

Another healthcare professional similarly had difficulties with discussing the topic of which patients do and do not use the technology.

[I: regarding these patients, is there anything in their social background, gender or ethnic background [that you have noticed]? No, there's something of everything. Single people, married people. People who still work, people who retired a long time ago. People that are in out-patient clinics or aged care facilities, something of everything. What you do see, what you notice, most people are people that are a bit more capable than the average Dutch person, so to say. Just because it is quite complicated. Because you need to be up for it.

Grace, nurse practitioner (w)

This nurse practitioner also starts answering this question by stating that the patients come from a variety of backgrounds. Even though the interviewer prompted her to discuss social backgrounds such as gender and ethnicity, she explains the variety of backgrounds by talking about differences between patients in marital status, job status, and stages of disease. Again, 
this seemingly constructs those categories as easier to discuss rather than the more uncomfortable differences between different genders or ethnicities. Moreover, she follows that explanation of different backgrounds by acknowledging that patients who join the POHCs need to possess certain capabilities, and more so than the 'average Dutch person'. She relates this to the POHC being 'quite complicated' and that you have 'to be up' for working with it. Therefore, even though this nurse practitioner does explicitly acknowledge differences based on social categories, she still identifies certain required abilities, which we will further unpack in the sections below.

\section{Downplaying differences}

Other healthcare professionals did talk openly about differences between patients. When healthcare professionals acknowledged differences between patients, they found different ways to engage with them. In the next section, we discuss the second practice, downplaying differences. Healthcare professionals frame differences among patients as rather innocent, framing them as individual differences and so downplay their impact.

This [the POHC] is too complicated, especially for patients with Parkinson's, too many actions to get somewhere. And I think that 10 years from now, we'll have a very different population. So, people who already know a lot more about computers. 
I think that the 60-year-olds, the 70-year-olds, a lot can work a bit with the computer, but a lot also can't. And that's currently an issue.

\section{Alicia, Parkinson's nurse (w)}

This nurse practitioner uses individualizing language to discuss the differences between patents, similar to how patients Peter and Howard talked about abilities a patient must have. Alicia discusses the use of POHCs in relation to cognitive functions. She explains that patients with Parkinson's disease might have a difficult time using the technology, both because of their cognitive functions and their age. Although she recognizes how cognitive functions and age have an influence, she also suggests that this issue will be resolved with time (when new generations with more technological abilities will grow older), downplaying the effects of cognition (and age). If we turn to critical diversity literature, we can reinterpret these declining cognitive functions in terms of disability.

Disability, seen as a social category and intersecting with that of ageing in general, is tied to a cultural meaning of lack and decline (Thomas, Hardy, Cutcher, \& Ainsworth, 2014). Becoming disabled comes with expectations that others might have about your functioning (Jammaers, Zanoni, \& Hardonk, 2016). Having difficulties with finding your words can cause others to assume you have less demands and, therefore, to be less fitting with consumerism of the POHCs. Lower expectations around those patients with diminishing 
cognitive functions might affect how they are approached by their healthcare professionals and might thus affect their care provision. Alicia's quote also shows how age (which, as Alicia constructs, is mostly generational) intersects with cognitive (dis)ability to affect how patients' use the POHC. She argues that the fact that they are from a generation that is not used to using computers adds to the disabilities that patients experience. As such, we witness a construction of those who are older and disabled that is based on stereotypical ideas surrounding these social categories (Thomas et al., 2014).

However, it is not just age and disability that play a role in having or not having the right technological skills, as Will, the neurologist, discusses:

How well-equipped people are to work with computers also has to do with their educational level. And also feeling comfortable to formulate what you want and are thinking... that does demand certain abilities that not everyone has. I haven't made a stratification of this, but my feeling is that it's a relatively high educated group. And for younger people it's less of an issue, because they're all used to doing things with computers. But then, when you look at beyond 60, then it's I think almost all higher educated. [...] I fear that with this older group, men are also better with computers than women. Because women have never done that, never learned it, so that will probably be connected. Men have often worked a bit with computers in their job. And that way, 
they learned it [...]. That's how they know what a computer is, and they have continued working with them. And some of the women have, because sometimes there also are relatively well-educated women, who email and chat with people around the world.

$$
\text { Will, neurologist (m) }
$$

According to Will, having enjoyed higher education is important for using the POHCs, because this affects one's technological skills, especially older patients'. The younger generation (as Alicia also suggested) is more used to working with computers and for them, Will believes, the effect of educational background will be smaller. Here we see education intersecting with gender and age. The neurologist reasons that the lack of work experience of older women has created a lack of technological skills. According to Will, only those women who are "relatively" well-educated might be able to use a computer, and, therefore, a POHC. In this construction of differences, Will gives a more structurally oriented reason for why women are in his opinion less able to use the POHCs; because today's Parkinson's women patients generally did not work with computers, they lack the technological knowledge that men were able to acquire during their professional lives. As he relates this to a historical reason rather than a natural ability, he explains the gender differences he 
experiences as a structural difference. However, he seems to assume this is merely a generational issue. In the future, this gender difference will be resolved.

Importantly, the healthcare professionals frame the differences in terms of individual traits except for Will's discussion of gender. Age and cognitive functions are framed as something individual, rather than something that is structured through one's belonging to certain (social) groups. As such, these practices downplay, and in a way erase, the significance of these differences for creating inequality in a similar way as not acknowledging the differences at all (which we saw David, the neurologist, do earlier).

The result of individualizing differences, and especially arguing that certain differences in use are due to generational issues, is that these differences are made rather innocuous. Following the interviewees' frame of thinking, these issues will either resolve on their own or are just due to randomly occurring individual differences. As such, individualizing does not threaten the standard that all patients are equal and deserve equal treatment. On the contrary, it allows healthcare professionals to acknowledge differences without being confronted with the uncomfortable side of it: the thought that these differences might be due to processes of structural inequality. Even though it does not threaten their sense of equal treatment, it simultaneously does not allow for discussing that this inequality exists. Moreover, the practices essentialize those differences; they are just there, rather than an 
outcome of our social constructions of 'meaningful' differences between people (Jonsen et al., 2013).

\section{Discomfort around acknowledging differences}

In the excerpt from Will, above, we see that he uses the phrase 'I fear' that older men are better at working with computers than older women. Such hesitance to mark differences is a practice we saw occurring more often, and we will analyze this in further depth in this section as we discuss the third practice. Take for example this excerpt from Robyn.

[I: you just said that some patients have an easier time articulating. What are...] I may not be allowed to say this, but those are often also the more highly educated.

[I: how does education play a role?] Well, understanding unfamiliar concepts. That you know how your body functions. Yes, that... lower educated just don't possess those communication techniques.

$$
\text { Robyn, physical therapist (w) }
$$

Robyn constructs how being articulate when conversing with healthcare professionals, entails understanding the concepts that are part of medical language. In her discussion, she explicitly refers to the importance of education in knowing such concepts. However, she also shows hesitance in being this explicit about the role of education as she states that this is something she "may not be allowed to say, but...”. Her choice of words shows that she is 
aware of the sensitive nature of linking patients' abilities to use the POHC to something like educational background.

Robyn's hesitance to discuss educational background is more easily understood when you link it to the term 'class'. Class is a concept that is associated with structural factors and lays bare the structural inequalities that the concept of educational background often conceals (Lareau, 2003). In the concept of class, the idea of transferring skills from generation to generation is much more present. These skills, further reproduced by 'education', are often not individually 'achieved', but structurally assigned to certain groups and harder to acquire by others (Gill, 2014). Bringing in this concept of class, therefore, reveals the structural inequalities embedded in, and reproduced by, consumerism; only those patients who have the 'right' class background, and therefore, the communications skills, fit the consumerist technology and benefit from its advantages. Consumerism only helps create further divisions among patients as education/class background not only influences use of language and knowing what to say, but also the actual use of and familiarity with technology (as Will argued before).

Similarly, a general practitioner comments on the exclusiveness of those patients who find their way onto the POHC: 
In the end it is active people, who are knowledgeable about technology, who find their way to this technology. The so-to-speak weaker, to put it in inverted commas, people who do not take control or who have a lot of issues around their disease, they do not find their way, they don't use these tools. I also notice this in my email consults. [People who use these] are more highly educated people who are quite healthy still.

\section{Eli, General Practitioner (m)}

This general practitioner recognizes that only a specific group of patients makes use of the POHCs. He explicitly mentions that those who are 'weaker' are excluded. Those 'so-to-speak weaker' patients are the patients who 'do not take control' or 'do not find their way to this technology' (which should give them a more active role and allow them to behave more like an individualized consumer). He links his division between patients explicitly to levels of education. Interestingly, he explicitly adds "in quotation marks" to his use of the word 'weaker', displaying a level of discomfort about being so explicit about the difference between patients and their abilities, discomfort that we also saw in Robyn's excerpt.

Arguably, this practice of discomfort around acknowledging differences most clearly exposes the tension healthcare professionals deal with. It suggests how hard it is for professionals to openly acknowledge differences, especially when it comes to the structural form these differences take. Normally, it remains unspoken that not all patients have the same opportunities because of inequalities deeply rooted in our societies. Because of the historical 
roots of structural inequalities, there is no easy fix. To acknowledge that and admit that patients who do not fit a certain social background will have a harder time making use of the POHCs clearly goes against the professionals' ethics of treating all patients equally. To make matters worse, professionals suggest that exactly those patients who do not get access to POHCs are already less involved in their own care to begin with, widening the division between different groups of patients.

\section{Actively accommodating differences}

We discuss the fourth and last practice in this section: actively accommodating differences.

[In the current version of the POHCs] the patient is free to decide on the content of their community and to manage their treatment plan, to put it that way. They just can't do that. That's already difficult for us, to really decide what the important aspects are of the treatment for this or that patient. And they just can't really oversee that [...] It would already be nice if you have a bit of a segregation, I am just thinking of this right now, a segregation in this. Because for one part of the people, you should just make it easy. They won't coordinate their whole treatment plan, but they should be helped with addressing those things that they think are important and then having an easy way of communicating. Like, bam! Log in like that and then just a couple of taps on the keyboard. And other people can easily, like that woman who has a lot of 
ideas about how it should be, she wants to be able to communicate about this, she wants to lay out her ideas. And there we should give her the means, so that she can do that even better. And then a third of Parkinson's patients, I think the group is about that big, can in that way easily manage his own treatment

Will, neurologist (m)

This excerpt suggests that the neurologist sees differences in how his patients use the POHCs. Although he does not indicate what causes those differences, we can deduct from his earlier quote that he believes age, gender, and education are important factors. He proposes addressing these differences by providing different versions of the POHCs. This practice of actively accommodating differences is a fourth way to resolve the tension between seeing difference and treating patients equally. This practice suggests giving patients a less or more complex POHC to work with, based upon the needs and desires of different groups. As such, all groups will get access to the POHC, without one group being excluded altogether and without pretending that all patients use the POHCs in the same way. Although this practice, at first sight, seems to ease the tension, there is also another side to it. By making this distinction between different patients, the neurologist is also drawing a line between the kinds of care patients have access to. The different platforms might exacerbate the differences between patients by giving certain patients the tools to take a more active role than others 
because their technological system allows for that. Although it might accommodate differences, it ultimately does not do anything to change those differences. Furthermore, professionals run the risk of essentializing differences among patients when making decisions about who gets the complex and who gets the simple platform.

A nurse practitioner offered a similar perspective on certain patients' inability to take on a consumer role, but reflects on her own role and responsibility in this process as well.

But I think you sometimes have to help patients a bit with taking charge. Because, very many patients become a bit cognitively impaired [...] But to only let this [care provision] happen through the POHCs, only make people reach out when they think it's possible, without any appointments in the meantime... I think that's going too far. I might not be allowed to say that, but that's what I think [laughs]

$$
\text { Grace, Parkinson's nurse (w) }
$$

Similar to what we have read before, Grace describes how cognitive functions are vital for patients knowing what they need and for actively asking for help, two important aspects of consumerism. At the same time, she describes how she feels she has a responsibility to help those patients who are less able to still achieve good outcomes. She explicitly critiques the idea that care provision should completely move to technology in the future, from the perspective that this will not be beneficial to all patients. Similar to the neurologist, she makes 
it clear that she is aware that the technology cannot serve all patients equally. However, she does not put the onus to change this inequality on the design of the technology but on herself and the support she offers. She seems to suggest that the technology will never be equally accessible to all patients, hence her argument that technology should not completely take over care provision (although she displays hesitance around this argument when she states "I might not be allowed to say this"). As a response to the promotion of technology in healthcare, she seems to suggest that healthcare professionals should actively accommodate these differences rather than expect the technology to do so.

\section{Discussion}

This article has developed a micro-level perspective of consumerist technology in healthcare, focusing specifically on the role consumerist technology plays in (re)producing social inequality. Drawing on critical diversity literature, we examined how healthcare professionals deal with the tension between providing individualized services and treating patients equally. This allowed us to make two theoretical contributions. The first contribution concerns understanding how the technology regulates access and (re)produces social inequalities, as consumerism assumes a 'universal individual', able to articulate needs and desires for care provision. The second contribution concerns the tension healthcare 
professionals experience in using the technology and theorizing how healthcare professionals engage in four practices that all end up 'doing difference without inequality'.

\section{Technology, access, and social inequality}

With our first contribution we show how communication technology marks access to care as a particular issue of consumerism. Consumerist technology positions patients as 'universal individuals' (all possessing the ability and desire to express their individual needs), whereas there is diversity in the desire and ability to do so. As such, access to the technology has become a point of contention. Although the discourse around technology boasts open access and catering to individual needs (Krist \& Woolf, 2011; ParkinsonNet, 2012), it simultaneously enables the production of new inequalities, by not allowing access to a diverse group of patients. Rather than increasing the involvement of all patients, the technology actually ends up widening the gap between diverse groups of patients, without providing the space to acknowledge and address these new inequalities.

However, this inequality does not only pertain to the access to the technology, it also affects the progressively increasing disability that most patients with Parkinson’s disease (or other chronic illnesses) might face. In other words, even when patients have access to the technology at some points, they are at risk of losing this access when their disease progresses and they are no longer (deemed) able to use the technology to communicate with their 
healthcare professionals, since the technology does not allow for diversity in disability (or other social categories) in its design.

\section{Tensions, healthcare professionals and their practices}

Our second contribution shows how healthcare professionals deal with the tension between difference and equality that is embedded in the technology. As such, we do not only demonstrate inequality in access to care through technology, but also theorize how professionals deal with this inequality. We have shown four practices through which healthcare professionals deal with this tension. Even though the practices differ in how they discuss differences among patients, the practices are similar in that they are all unable to address the (intersecting) social categories that lie at the basis of the inequality produced by consumerist technology.

However, because consumerism individualizes the differences among patients, it forces healthcare professionals into uncomfortable positions in which they lack the vocabulary to discuss those differences. Instead, healthcare professionals refer to these differences as individual characteristics, similar to what literature describes as differences in 'health literacy’ (Marmot, 2007; Rademakers, 2014). This term presents the abilities one needs to be actively using the POHCs as something that can be taught in a lesson, much like you have literacy programs. Using the term 'health literacy', instead of the social categories 
it silences, conceals the political and structural nature of the inequality produced through consumerism. Therefore, although the individualizing of differences might ease the tension healthcare professionals experience between acknowledging differences while aiming for equal treatment of all, it ultimately does nothing to eradicate the inequality produced by consumerism embedded in the technology, or at least does not do justice to the inequality that exists between these 'unequal consumers'. In other words, we theorize that healthcare professionals end up ‘doing difference without inequality’.

Although the practice of actively accommodating differences goes furthest in understanding inequalities as a systematic issue that needs to be addressed, the solutions offered by healthcare professionals vary wildly, suggesting either separate versions of the technology or increased responsibility for the healthcare professionals to take on what the technology cannot offer.

\section{Ethics of care}

With our criticism of the social inequality created by consumerist technology, we want to acknowledge the predicament that healthcare professionals are in. Viewing their practices in light of an 'ethics of care’ (Ashcroft, Dawson, Draper, \& McMillan, 2007; Seedhouse, 2008), we emphasize that in professionals' experience, not focusing on one's background might seem more ethical compared to stressing those issues (creating the possibility of putting 
people in particular boxes). Therefore, we can debate what an ethics of care entails in consumerist technology, and this inability to define ethical behavior is also part of a general discussion in healthcare. Some see the word 'care' itself as being paternalistic, while for others it is an emancipatory word, allowing for the inclusion of marginalized people (Hughes et al., 2005). We recognize similar disputes in our data as well. Where some healthcare professionals indicate to rather not focus on differences, others are looking for active ways of accommodating them. We, ourselves, also cannot provide a clear answer to what an ethics of care entails in the context of this consumerist technology. At this point, we only feel able to state that initiators of technology should be aware of the diverse audience they proclaim to cater to. Even though some interviewees see this diversity mostly in terms of age, suggesting that aspects of this inequality are generational, we argue that this paints too bright a picture of the future. Using technology is not just about knowing how to switch on a computer, but also about how to express oneself in a way that fits the demanding and proactive ideal patient as created by consumerism embedded in the technology. Linking back to the two solutions defined by the healthcare professionals who seek to accommodate differences, we suggest that this could be done by both redesigning the technology as well as ensuring that healthcare professionals are sensitive to different abilities that patients may 
have, similar to how Mol (2008) suggests adopting a logic of care, rather than a logic of choice.

\section{Generalizing our findings: consumer ethos and technology in public services}

Although we have examined consumerism in the healthcare sector, this ethos is present in many other public services (Gabriel et al., 2015; Jung, 2010), taking the form of a moral doctrine propagating freedom and empowerment (Fotaki, 2009). For example, in social welfare or the education sector, recipients of such services are increasingly positioned as consumers under the guise of neo-liberalism (Giroux, 2002; Ilcan, 2009; Martin, 2004; Naidoo \& Williams, 2015). Superficially, this seems to lead to more efficient service provision where the 'consumers' have more control, but we would theorize these processes as producing 'universal individuals' - much like we have seen happen with patients in this article - where only an exclusive group gets access to this role that also comes with an increased responsibility for the outcomes of this service provision.

Our focus on technology explains why our findings translate to other contexts as well; consumerism and technology often go together (Josefsson \& Ranerup, 2003). Technology brings in the important theme of access, since technology is not self-evidently used by all. Other public services, such as unemployment agencies have also undergone technologification, and scholars have questioned the effect this has on the access people have 
to such IT-based services (Warschauer, 2004). The design of these technologies does not acknowledge, let alone provides any support for, people from different social backgrounds, and this is a shared, but often unacknowledged, predicament of the increasing use of technology in our societies (DiMaggio \& Hargittai, 2001; van Dijk, 2005).

Most importantly, our article demonstrates that consumerist technology only reaches the 'low-hanging fruit'. As a result, this strategy of targeting the 'within-reach' individuals, works to exclude certain groups of social categories, and, therefore, is a potentially dangerous strategy for increasing the quality of service provision. Because there is often an absence of recognition of the political nature of these exclusionary practices (Calás, Ou, \& Smircich, 2013; Garland \& Darcy, 2009), the dominance of consumerism becomes part of the 'systemic dynamics of power' through which already existing inequalities become further institutionalized (Rodriguez, Holvino, Fletcher, \& Nkomo, 2016, p. 202). The potentially negative effects of this consumerism are only further exacerbated by the fact that it uses the language of emancipation or empowerment to sell the consumerization of service users (Krist \& Woolf, 2011; Prainsack, 2014). Even though these concepts are drawn upon, we have shown that they are not accompanied by a discussion of the systemic change that is required to achieve actual emancipation (Hardy \& Leiba-O'Sullivan, 1998). 
If we take our analysis of consumerism (in healthcare) one step further, we can bring in the topic of competition as well. Competition does not only exist between service providers (healthcare professionals) or organizations who want to 'produce' or provide as much as possible. Professionals' time has also become a scarce resource to compete for. As such, consumers that have less 'commodity value' or are 'flawed', because they do not easily fit into the image of the active, responsible consumer, might become less attractive to provide for (Bauman, 2007). Communication technology might give certain consumers an extra impulse to have a leg up in this competition because of the relatively low time investment and larger flexibility the technology provides for professionals. This competition could prove to be a fruitful avenue for future research, especially to further understand what happens when the use of technology will become increasingly normalized (and financially rewarded). We might find that this only further cements social inequality, leaving certain groups of consumers to become, what Zygmunt Bauman (2011) calls, the 'collateral damage' of this push toward technology from consumerism.

\section{References}

Arnould, E. J., \& Cayla, J. (2015). Consumer Fetish: Commercial Ethnography and the Sovereign Consumer. Organization Studies, 36(10), 1361-1386. 
Ashcroft, R. E., Dawson, A., Draper, H., \& McMillan, J. (2007). Principles of Health Care Ethics. Cambridge, UK: Wiley.

Bartley, M. (2004). Health Inequality: An Introduction to Concepts, Theories and Methods. Cambridge, UK: Wiley.

Baudrillard, J. (1998). The Consumer Society: Myths and Structures. New York, NY: Sage.

Bauman, Z. (2007). Consuming Life. Cambridge, UK: Wiley.

Bauman, Z. (2011). Collateral Damage: Social Inequalities in a Global Age. Cambridge, UK: Wiley.

Benschop, Y. W. M. (2011). The Dubious Power of Diversity Management. In S. Gröschl (Ed.), Diversity in the Workplace: Multi-Disciplinary and International Perspectives (pp. 15-28). Surrey, UK: Taylor \& Francis

Bryman, A., \& Bell, E. A. (2012). Social Research Methods. Oxford, UK: Oxford University Press.

Burge, P., Devlin, N., Appleby, J., Rohr, C., \& Grant, J. (2005). London Patient Choice Project Evaluation. Advance online publication. doi:

Calás, M. B., Ou, H., \& Smircich, L. (2013). “Woman” on the Move: Mobile Subjectivities after Intersectionality. Equality, Diversity and Inclusion: An International Journal, 32(8), 708731.

Caruana, R., \& Crane, A. (2008). Constructing Consumer Responsibility: Exploring the Role of Corporate Communications. Organization Studies, 29(12), 1495-1519.

Crawshaw, P. (2012). Governing at a Distance: Social Marketing and the (Bio) Politics of Responsibility. Social Science \& Medicine, 75(1), 200-207. 
Dent, M. (1995). The New National Health Service: A Case of Postmodernism? Organization Studies, 16(5), 875-899.

Detmer, D., Bloomrosen, M., Raymond, B., \& Tang, P. (2008). Integrated Personal Health Records: Transformative Tools for Consumer-Centric Care. BMC Medical Informatics and Decision Making, 8(1), 45.

DiMaggio, P., \& Hargittai, E. (2001). From the 'Digital Divide’to 'Digital Inequality': Studying Internet Use as Penetration Increases. Working paper, Center for Arts, Culture \& Policy Studies, Princeton University.

Dwarswaard, J., Hilhorst, M., \& Trappenburg, M. (2011). The Doctor and the Market: About the Influence of Market Reforms on the Professional Medical Ethics of Surgeons and General Practitioners in the Netherlands. Health Care Analysis, 19(4), 388-402.

Fontenelle, I. A. (2015). Organisations as Producers of Consumers. Organization, 22(5), 644-660.

Fotaki, M. (2006). Choice Is Yours: A Psychodynamic Exploration of Health Policymaking and Its Consequences for the English National Health Service. Human Relations, 59(12), 1711-1744. Fotaki, M. (2009). Are All Consumers the Same? Choice in Health, Social Care and Education in England and Elsewhere. Public Money \& Management, 29(2), 87-94.

Fotaki, M. (2010a). Patient Choice and Equity in the British National Health Service: Towards Developing an Alternative Framework. Sociology of Health \& Illness, 32(6), 898-913.

Fotaki, M. (2010b). Why Do Public Policies Fail So Often? Exploring Health Policy-Making as an Imaginary and Symbolic Construction. Organization, 17(6), 703-720. 
Fotaki, M. (2011). Towards Developing New Partnerships in Public Services: Users as Consumers, Citizens and/or Co-Producers in Health and Social Care in England and Sweden. Public Administration, 89(3), 933-955.

Fotaki, M. (2017). Relational Ties of Love - a Psychosocial Proposal for Ethics of Compassionate Care in Health and Public Services. Psychodynamic Practice, 23(2), 181-189.

Fotaki, M., Roland, M., Boyd, A., Mcdonald, R., Scheaff, R., \& Smith, L. (2008). What Benefits Will Choice Bring to Patients? Literature Review and Assessment of Implications. Journal of Health Services Research \& Policy, 13(3), 178-184.

Gabe, J., Harley, K., \& Calnan, M. (2015). Healthcare Choice: Discourses, Perceptions, Experiences and Practices. Current Sociology, 63(5), 623-635.

Gabriel, Y., Korczynski, M., \& Rieder, K. (2015). Organizations and Their Consumers: Bridging Work and Consumption. Organization, 22(5), 629-643.

Gabriel, Y., \& Lang, T. (2008). New Faces and New Masks of Today's Consumer. Journal of Consumer Culture, 8(3), 321-340.

Garland, D., \& Darcy, M. (2009). 'Working Together?’: The Salvation Army and the Job Network. Organization, 16(5), 755-774.

Gill, R. (2014). ‘If You're Struggling to Survive Day-to-Day’: Class Optimism and Contradiction in Entrepreneurial Discourse. Organization, 21(1), 50-67.

Giroux, H. (2002). Neoliberalism, Corporate Culture, and the Promise of Higher Education: The University as a Democratic Public Sphere. Harvard Educational Review, 72(4), 425-464. 
Hardy, C., \& Leiba-O'Sullivan, S. (1998). The Power Behind Empowerment: Implications for Research and Practice. Human Relations, 51(4), 451-483.

Henwood, F., Harris, R., \& Spoel, P. (2011). Informing Health? Negotiating the Logics of Choice and Care in Everyday Practices of 'Healthy Living'. Social Science \& Medicine, 72(12), 2026-2032.

Hughes, B., McKie, L., Hopkins, D., \& Watson, N. (2005). Love’s Labours Lost? Feminism, the Disabled People’s Movement and an Ethic of Care. Sociology, 39(2), 259-275.

Ilcan, S. (2009). Privatizing Responsibility: Public Sector Reform under Neoliberal Government. Canadian Review of Sociology/Revue canadienne de sociologie, 46(3), 207-234.

Jammaers, E., Zanoni, P., \& Hardonk, S. (2016). Constructing Positive Identities in Ableist Workplaces: Disabled Employees’ Discursive Practices Engaging with the Discourse of Lower Productivity. Human Relations, 69(6), 1365-1386.

Jonsen, K., Tatli, A., Özbilgin, M. F., \& Bell, M. P. (2013). The Tragedy of the Uncommons: Reframing Workforce Diversity. Human Relations, 66(2), 271-294.

Josefsson, U., \& Ranerup, A. (2003). Consumerism Revisited: The Emergent Roles of New Electronic Intermediaries between Citizens and the Public Sector. Information Polity: The International Journal of Government \& Democracy in the Information Age, 8(3/4), 167-180.

Jung, T. (2010). Citizens, Co-Producers, Customers, Clients, Captives? A Critical Review of Consumerism and Public Services. Public Management Review, 12(3), 439-446. 
Krist, A. H., \& Woolf, S. H. (2011). A Vision for Patient-Centered Health Information Systems. JAMA, 305(3), 300-301.

Laing, A., \& Hogg, G. (2002). Political Exhortation, Patient Expectation and Professional Execution: Perspectives on the Consumerization of Health Care. British Journal of Management, 13(2), 173-188.

Lareau, A. (2003). Unequal Childhoods: Class, Race, and Family Life. Berkeley, CA: University of California Press.

Long, S. (1999). The Tyranny of the Customer and the Cost of Consumerism: An Analysis Using Systems and Psychoanalytic Approaches to Groups and Society. Human Relations, 52(6), 723-743.

Lorbiecki, A., \& Jack, G. (2000). Critical Turns in the Evolution of Diversity Management. British Journal of Management, 11(3), S17-S31.

Lupton, D. (1997). Consumerism, Reflexivity and the Medical Encounter. Social Science \& Medicine, 45(3), 373-381.

Marmot, M. (2007). Achieving Health Equity: From Root Causes to Fair Outcomes. The Lancet, 370(9593), 1153-1163.

Martin, S. (2004). Reconceptualising Social Exclusion: A Critical Response to the Neoliberal Welfare Reform Agenda and the Underclass Thesis. Australian Journal of Social Issues, 39(1), 7994. 
McDonald, R., Mead, N., Cheraghi-Sohi, S., Bower, P., Whalley, D., \& Roland, M. (2007). Governing the Ethical Consumer: Identity, Choice and the Primary Care Medical Encounter. Sociology of Health \& Illness, 29(3), 430-456.

Mol, A. (2008). The Logic of Care: Health and the Problem of Patient Choice. New York, NY: Routledge.

Naidoo, R., \& Williams, J. (2015). The Neoliberal Regime in English Higher Education: Charters, Consumers and the Erosion of the Public Good. Critical Studies in Education, 56(2), 208223.

Needham, C. (2009). Interpreting Personalization in England's National Health Service: A Textual Analysis. Critical Policy Studies, 3(2), 204-220.

ParkinsonNet. (2012). Mijnp@Rkinsonzorg Retrieved December 13, 2012, from http://www.parkinsonnet.nl/video's/parkinsonnet-video's/mijnp@rkinsonzorg

Prainsack, B. (2014). The Powers of Participatory Medicine. PLoS Biol, 12(4), e1001837.

Rademakers, J. (2014). Kennissynthese: Gezondheidsvaardigheden: Niet Voor Iedereen Vanzelfsprekend. (9789461222657). Utrecht: NIVEL.

Ravn, I. M., Frederiksen, K., \& Beedholm, K. (2016). The Chronic Responsibility: A Critical Discourse Analysis of Danish Chronic Care Policies. Qualitative Health Research, 26(4), 545-554.

Ritzer, G., Dean, P., \& Jurgenson, N. (2012). The Coming of Age of the Prosumer. American Behavioral Scientist, 56(4), 379-398. 
Ritzer, G., \& Jurgenson, N. (2010). Production, Consumption, Prosumption: The Nature of Capitalism in the Age of the Digital 'Prosumer'. Journal of Consumer Culture, 10(1), 13-36.

Rodriguez, J. K., Holvino, E., Fletcher, J. K., \& Nkomo, S. M. (2016). The Theory and Praxis of Intersectionality in Work and Organisations: Where Do We Go from Here? Gender, Work \& Organization, 23(3), 201-222.

Rogers, W. A. (2006). Feminism and Public Health Ethics. Journal of Medical Ethics, 32(6), 351354.

Schwandt, T. A. (2000). Three Epistemological Stances for Qualitative Inquiry: Interpretivism, Hermeneutics and Social Constructivism. In N. K. Denzin \& Y. S. Lincoln (Eds.), The Handbook of Qualitative Research (pp. 189-213). London: Sage.

Seedhouse, D. (2008). Ethics: The Heart of Health Care. Cambridge: Wiley.

Stevenson, F. A., Leontowitsch, M., \& Duggan, C. (2008). Over-the-Counter Medicines: Professional Expertise and Consumer Discourses. Sociology of Health \& Illness, 30(6), 913-928.

Thomas, R., Hardy, C., Cutcher, L., \& Ainsworth, S. (2014). What's Age Got to Do with It? On the Critical Analysis of Age and Organizations. Organization Studies, 35(11), 1569-1584.

Timmermans, S., \& Oh, H. (2010). The Continued Social Transformation of the Medical Profession. Journal of Health and Social Behavior, 51(1_suppl), S94-S106.

Tonkens, E. H. (2003). Mondige Burgers, Getemde Professionals: Marktwerking, Vraagsturing En Professionaliteit in De Publieke Sector. Amsterdam: Van Gennep. 
Tonkens, E. H., Broer, C., van Sambeek, N., \& van Hassel, D. (2013). Pretenders and Performers: Professional Responses to the Commodification of Health Care. Social Theory \& Health, 11(4), 368-387.

Turner, B. S., \& Samson, C. (1995). Medical Power and Social Knowledge. London: Sage.

van Dijk, J. (2005). The Deepening Divide: Inequality in the Information Society. Thousand Oaks, California: Sage.

Victoor, A., Delnoij, D. M., Friele, R. D., \& Rademakers, J. J. (2012). Determinants of Patient Choice of Healthcare Providers: A Scoping Review. BMC Health Services Research, 12(1), 272.

Victoor, A., Friele, R. D., Delnoij, D. M., \& Rademakers, J. J. (2012). Free Choice of Healthcare Providers in the Netherlands Is Both a Goal in Itself and a Precondition: Modelling the Policy Assumptions Underlying the Promotion of Patient Choice through Documentary Analysis and Interviews. BMC Health Services Research, 12(1), 441.

Warschauer, M. (2004). Technology and Social Inclusion: Rethinking the Digital Divide. Cambridge, MA: MIT Press.

Zanoni, P., \& Janssens, M. (2004). Deconstructing Difference: The Rhetoric of Human Resource Managers’ Diversity Discourses. Organization Studies, 25(1), 55-74.

Zanoni, P., Janssens, M., Benschop, Y., \& Nkomo, S. (2010). Guest Editorial: Unpacking Diversity, Grasping Inequality: Rethinking Difference through Critical Perspectives. Organization, 17(1), 9-29. 